\title{
Collector cable design based on dynamic line rating for wind energy applications
}

\author{
A.H. Wijethunga ${ }^{1,2^{*}}$, J.B. Ekanayake ${ }^{2}$ and J.V. Wijayakulasooriya ${ }^{2}$ \\ ${ }^{\prime}$ Sri Lanka Technology Campus, Padukka. \\ ${ }^{2}$ Department of Electrical and Electronic Engineering, Faculty of Engineering, University of Peradeniya, Peradeniya.
}

Revised: 27 May 2017; Accepted: 17 August 2017

\begin{abstract}
Wind power will play a major role in future power generation systems. In order to promote more and more wind farm connections, the capital cost (CAPEX) should be minimised. In this paper a novel concept is presented based on two practical considerations, namely, the actual current through different sections of a radially connected wind turbine string reduces from the substation end to the farthest wind turbine; and the current carrying capacity of a conductor and wind turbine current increases with the wind speed. Two tools that support the design of the collector network and ensure safe operation of the overhead collector conductors were developed. The first tool aids the designing of the collector conductors based on the dynamic line rating of the conductor and the actual wind farm output at different wind speeds. The second tool is a verification tool, which ensures that the conductor core temperature does not exceed the maximum allowable conductor temperature. A case study is presented to demonstrate the use of the design tool whereas a real life implementation is used to demonstrate that the verification tool can be used in a real wind farm to ensure the safety of the conductors.
\end{abstract}

Keywords: Collector network, dynamic line rating, wind power.

\section{INTRODUCTION}

In response to climate change, many governments have set ambitious targets to increase the use of renewable energy to reduce greenhouse gas emissions. Generating electricity from the wind is one of the more cost effective ways of using renewable energy. As at the end of 2015, the total installed global capacity of wind is about $486 \mathrm{GW}$ and is continuously growing.

Wind turbines generate a relatively low voltage, usually below $1000 \mathrm{~V}$. With this generator voltage it is necessary for each turbine to have an individual transformer either within or adjacent to the tower. This increases the voltage for connection to the power collection network, for example to $33 \mathrm{kV}$. A central wind farm transformer steps up the voltage to $132 \mathrm{kV}$ or $220 \mathrm{kV}$ for connection to the public network.

In typical substation and infrastructure design emphasis is always given to the service continuity and reliability, thus adequate redundancy and transfer capabilities are embedded in the design. As the output of a wind farm is variable and intermittent, for a wind farm, the requirements for service continuity and reliability are not as critical as economics and availability (Camm et al., 2009a).

The IEEE Power and Energy Society (PES) wind plant collector system design working group published a number of papers covering different aspects of collector system design (Camm et al., 2009a; 2009b; Bradt et al., 2010). In all these papers the configuration proposed is a 'daisy chain' style connection that connects wind turbines by a cable or an overhead network. The number of wind turbine generators placed on a feeder string is limited by the static rating of the conductor, and the

* Corresponding author (aki.wijethunga@gmail.com; iD https://orcid.org/0000-0002-7672-6583)

This article is published under the Creative Commons CC-BY-ND License (http://creativecommons.org/licenses/by-nd/4.0/). This license permits use, distribution and reproduction, commercial and non-commercial, provided that the original work is properly cited and is not changed anyway. 
size of the conductor from the substation to the furthest located turbine is chosen based on the static rating.

Conductor cost has a significant effect on the infrastructure cost of a collector network, which has to be optimised considering different available conductor types and sizes (Cerveira et al., 2016). Due to material and installation costs, wind farm developers try to place as much generation on a feeder cable as possible. In order to minimise cable failures that result in costly downtime of the wind farm, cables should be properly sized considering the thermal characteristics of the soil in which the cable is buried (Rosen et al., 2010).

The optimal collector system design that minimises the voltage drop and losses of the collector network also has a significant bearing on the lifetime cost of the wind farm (Dutta \& Overbye, 2012). Dutta and Overbye (2011) proposed a clustering based cable layout configuration. The total cost and losses associated with the proposed layout is compared with a radial feeder string connection. An algorithm to optimise the collector cable network while considering the trenching constraints is presented in Dutta and Overbye (2013). The analysis of the thermal stress in collector system feeders and how the current carrying capacity (CCC) of the cable is substantially reduced when considering the limits specified by the Canadian design codes are discussed in Enrique et al. (2014). Afanasyeva et al. (2016) presented a wind farm collector network design based on the sum of the annual infrastructure costs. The proposed method is a two-step optimisation process in which the roads are first found using Dijkstra's algorithm and the collector system is optimised by Cuckoo search algorithm.

Most of the literature discuss about selecting suitable cables, cable trenching and optimum cable network for wind farm collector system. Although the predominant installations, to date, have been underground, considering the lower cost and ease of maintenance and repairing, overhead conductors are being considered for collector networks in some regions (Wu et al., 2011). For a given unit cost, an overhead conductor allows more power delivery compared to an underground cable, sometimes up to $40-50 \mathrm{MW}$ per single string.

In all studies discussed above, conductors for the entire collector network is selected based on the maximum possible current in the string of wind turbines and the static rating of the conductors. In this paper a novel concept based on two practical considerations is presented. The first consideration is based on the fact that towards the end of the string power from a few turbines is flowing, whereas at the beginning power from the entire wind farm is flowing. Therefore, it is more economical to use tapered conductors where the cross sectional area of the conductor towards the end of the string is much smaller than that at the beginning of the string. The second consideration is based on the fact that the CCC of a conductor depends on the heat balance on the conductor and when the wind blows, more heat is taken away from a conductor quickly (Douglas et al., 1997). Therefore when the wind speed is high, even under high currents flowing through the conductor, the heat produced by the copper $\left(I^{2} R\right)$ losses of the conductor will not increase the temperature of the conductor beyond the allowable limit. This in turn increases the CCC of the conductor. As the current flowing through a collector conductor within a wind farm is proportional to the cube of the wind speed, the above phenomena was used to optimise the cross sectional area of the collector conductors on top of the tapered design.

Although the heat balance phenomena is theoretically sound, in practice due to the large span on the collector network, hot spots could be developed thus requiring sensing devices to continuously sense the conductor temperature and make sure that the core temperature does not exceed the maximum allowable temperature. In order to check this, a sensing device and a verification tool were also developed.

\section{Current carrying capacity of an overhead conductor}

The theoretical value of the static rating of a conductor is the $\mathrm{CCC}$ calculated considering the maximum allowable conductor temperature and physical properties of the conductor and the desired weather conditions (Deb, 2000; Power Delivery Consultants, Inc, 2013).

The maximum conductor temperature, $T_{c}(\max )$, is considered as an important parameter when assessing the thermal behaviour of a conductor. The temperature and the sag increase with the current flowing through a conductor. If the maximum allowable sag is exceeded, flashovers may occur. Therefore, the designed temperature of a conductor is used as a parameter to determine the clearance to the ground and nearest objects (Power Delivery Consultants, Inc, 2013).

If a conductor is subjected to high temperature for a longer period, it may cause mechanical damage to the conductor or even recrystallisation of the material. The strength of a conductor and its tension decrease if the conductor surpasses the maximum allowable conductor temperature. Once the conductor reaches the inelastic 
elongation region, the sag is irreversibly increasing. Therefore, it is important to operate the lines below the maximum permissible conductor temperature (Kiessling et al., 2003).

The maximum permissible conductor temperature is decided by the manufacturer based on the maximum sag and the maximum losses of the conductor. Based on the maximum conductor temperature and worst-case weather conditions, manufactures define the static rating of a conductor. When determining the static rating, the lowest wind speed, highest ambient temperature, and highest solar radiation conditions are assumed based on historical weather data of the region. A wind speed of $0.6 \mathrm{~ms}^{-1}$ and ambient temperature close to the annual maximum of ambient temperature along the line route are usually used to calculate the static rating of conductors (IEEE Std 738 ${ }^{\mathrm{TM}}, 2012$ ). The current practice is to design the collector network of a wind farm using the static rating (Bradt et al., 2010).

\section{METHODOLOGY}

A tool was developed to obtain the optimum design of the collector network based on dynamic line rating. This tool calculates the dynamic line rating based on the wind conditions and compare it with the actual wind farm output. When the dynamic line rating is used to design conductors for the collector network, conductors operate closer to their thermal limit. Therefore, in order to make sure that the lines are operating safely, it is necessary to check whether the maximum temperature in the conductor in real time is less than the maximum allowable conductor temperature. This condition was checked in real time by obtaining the core temperature of the conductor from the measured surface temperature.

\section{Design tool to determine the conductor size based on the dynamic line rating}

An algorithm was developed to calculate the dynamic line rating of a conductor using the real time measurements of wind speed obtained from the wind farm. The actual wind farm output and the dynamic line rating of the collector conductors were used to select the best suited conductor for the wind farm collector network. In between cut-in wind speed to the rated wind speed, the wind farm output is proportional to the cube of the wind speed thus less current flows in the collector network. However, at low wind speeds the heat dissipation due to convection is less thus showing lower dynamic line rating. On the other hand, from the rated wind speed to cut-out wind speed, the wind farm power output is constant but more heat is dissipated. Therefore, the required conductor sizes from the cut-in to the rated wind speeds were obtained and the maximum value plus a safety margin is used to determine the required conductor size.

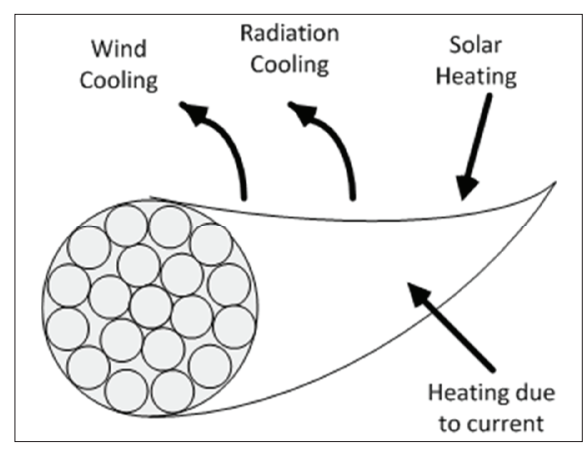

Figure 1: Heat balance of an overhead conductor

For an overhead conductor the thermal state can be obtained by balancing the heat gain and heat loss of the conductor. Different heating and cooling effects associated with an overhead line are shown in Figure 1.

The conductor is in steady state heat balance when the heat absorption and heat dissipation is equal. The amount of heat absorbed depends on Joule heating and solar heating whereas heat dissipation depends on convective and radiative cooling (IEEE Std 738 2012). Joule heating is the heat input due to the current flowing in the conductor, which depends on conductor temperature. The heat output due to convection changes with the wind speed, ambient temperature and conductor temperature. The radiation heat output is a function of ambient temperature and conductor temperature (Deb, 2000; IEEE Std 738 ${ }^{\mathrm{TM}}$, 2012).

The heat balance equation for the power line shown in Figure 2 is defined as (Deb, 2000; IEEE Std 738 2012):

$q_{c}+q_{r}+m C_{p} \frac{d T_{c}}{d t}=q_{s}+I^{2} R_{a c}\left(T_{c}\right)$

where

$q_{s}$ is the heat absorption due to solar radiation

$q_{c}$ is the heat dissipation due to convection

$q_{r}$ is the loss of the radiation heat

$I^{2} R_{a c}\left(T_{c}\right)$ is the heat generated due to line current, $I$

$T_{c}$ is the conductor temperature

$m$ is the mass density

$C_{p}$ is the specific heat capacity 
$R_{a c}$ is calculated using the following equation (Deb, 2000):

$R_{a c}=R_{d c} K_{a c}\left[1+\alpha_{0}\left(T_{c}-T_{0}\right)\right]$

where

$T_{c}$ is the conductor temperature

$T_{0}$ is the initial temperature

$R_{d c}$ is the dc resistance at reference temperature

$K_{a c}$ is the ratio of ac resistance to dc resistance

$\alpha_{0}$ is the temperature coefficient of resistance

The value of $q_{s}$ is calculated using (Deb, 2000):

$q_{s}=\alpha_{s} D\left(S_{b}+S_{d}\right)$

where

$\alpha_{s}$ is the solar absorption

$D$ is the conductor diameter

$S_{b}$ is the beamed solar radiation

$S_{d}$ is the diffused solar radiation

The parameter $q_{c}$ is calculated using equation (4) (Deb, 2000):

$q_{c}=\pi\left(T_{c}-T_{a}\right)\left(\lambda\left(0.64 \mathrm{Re}^{0.2}+0.2 \mathrm{Re}^{0.61}\right) \times k_{w d}\right)$

where

$\operatorname{Re}=D\left(\frac{W}{V_{f}}\right)$

$D$ is the diameter of the conductor

$W$ is the wind speed

$\lambda$ is the thermal conductivity of ambient air

$V_{f}$ is the kinematic viscosity of air

$k_{w d}$ is the wind direction

$T_{a}$ is the ambient temperature

The parameter $q_{r}$ has $T_{a}$ and $T_{c}$ as input parameters as given in equation (5) (Deb, 2000):

$q_{r}=\sigma \varepsilon \pi D\left[\left(T_{c}+273\right)^{4}-\left(T_{a}+273\right)^{4}\right]$

where

$\sigma$ is Stephan Boltzmann constant

$\varepsilon$ is emissivity

Equations (1) to (5) were used to determine the dynamic line rating, $I$. Actual wind measurement from the wind farms were used in equation (4) and $T_{c}$ was taken as $T_{c}(\max )$. This gives the CCC of the conductor for a given wind speed.

\section{Verification tool based on the core temperature of a conductor}

The thermal safety of the conductor depends on the highest possible temperature within the conductor, i.e. the core temperature. Therefore, it is essential to estimate the temperature of the innermost strand (core temperature) from the surface temperature measurements. For solid and stranded circular cylindrical conductors, the radial temperature distribution is considered to obtain the temperature difference in layers (Morgan, 1990). Depending on the number of contacts per unit length and the area of each contact, the core temperature and surface temperature difference was analysed (Morgan, 1990). Considering the cross section of an overhead conductor as given in Figure 2, a method of calculating the core temperature $\left(\mathrm{T}_{\mathrm{cl}}\right)$ was obtained.

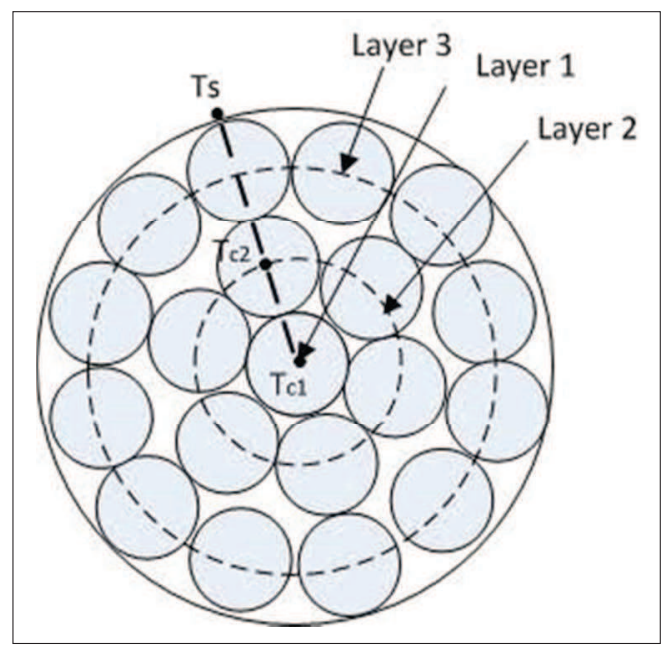

Figure 2: Cross section of an overhead conductor

Assuming that the current flowing in each strand is equal, the heat transfer from layer 1 to layer 2 through conduction was calculated using equation (6) (Jenkins \& Ekanayake, 2017):

$I_{0}^{2} R_{a c}\left(T_{c 1}\right)=\frac{k A_{1}\left(T_{c 1}-T_{c 2}\right)}{S_{1}}$

where,

$I_{o}$ is the current per strand

$T_{c 1}$ is the temperature of inner layer

$T_{c 2}$ is the temperature of second layer

$k$ is the thermal conductivity

$A_{1}$ is the heat transfer area of layer 1

$S_{1}$ is the material thickness of layer 1 
The heat transfer area is considered as the contact area of two cylinders with parallel axes as given in equation (7) (Johnson, 1985):

$$
A_{1}=\sqrt{\frac{\left(2 \times d \times r_{1} \times r_{2}\right)}{\left(r_{1}+r_{2}\right)}}
$$

where,

$d$ is the depth of indentation

$r_{1}$ and $r_{2}$ are the radius of contacted strands

At the surface layer, there will be heat gain due to solar heating and heat loss due to convection and radiation (Deb, 2000; IEEE Std 738 ${ }^{\mathrm{TM}}$, 2012). The heat balance equation for layer 2 to layer 3 is given by:

$$
I_{0}^{2} R_{a c}\left(T_{s}\right)+C q_{s}+\frac{k A_{2} I_{0}^{2}}{S_{2}}\left[T_{c 2}-T_{s}\right]=C\left(q_{c}+q_{r}\right)
$$

where

$q_{s}, q_{c}$ and $q_{r}$ are the heat absorption due to solar radiation, heat dissipation due to convection and heat loss due to radiation, respectively.

$I_{0}^{2} R_{a c}\left(T_{c}\right)$ is the heat generated due to line current, $I$ $A_{2}$ is the heat transfer area of layer 2

$S_{2}$ is the thickness of layer 2 to surface

$C$ is the ratio of area of the layer 3 in contact with atmosphere with total area

Equation (9) gives the calculation of the core temperature using the heat balance equation for the conductor by combining equations (6) and (8). According to the number of layers of strands, this equation needs to be expanded.

$$
I_{0}^{2} R_{a c}\left(T_{s}\right)+\frac{k A_{2} I_{0}^{2}}{S_{2}}\left[T_{c 1}-T_{s}-\left(\frac{I_{0}^{2} R_{a c}\left(T_{c 1}\right) S_{1}}{k A_{1}}\right)\right]=\left(q_{c}+q_{r}\right)
$$

where

$\mathrm{T}_{\mathrm{s}}$ is the surface temperature.

Using equation (9), the real time core temperature $\left(T_{c 1}\right)$ of the considered conductor was obtained from the measured surface temperature of the conductor. For safe operation of the conductor, $T_{c 1}$ should be less than the maximum allowable conductor temperature, which is usually taken as $75-80^{\circ} \mathrm{C}$.

\section{Wind farm collector conductor design}

The collector system used for this study is given in Figure 3. It consists of eight wind turbines. It was assumed that all the wind turbines are $3 \mathrm{MW}$ Vetas 90. It has a cut-in wind speed of $3.5 \mathrm{~ms}^{-1}$ and a rated wind speed of $15 \mathrm{~ms}^{-1}$. The step up transformer used to connect the wind farm to the collector network is a $1 / 33 \mathrm{kV}$ three phase transformer. The designing of the conductor size of the MV overhead lines from wind turbines to main substation at each line section was considered.

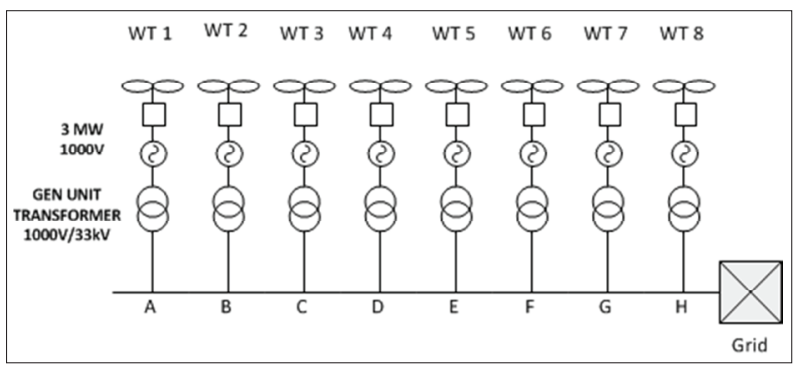

Figure 3: Wind turbine network

Conventional conductor design is based on equation (10). As per the IEEE Std 738 ${ }^{\mathrm{TM}}$ (2012) and current industry practices, it was assumed that the worst-case weather conditions are wind speed of $0.6 \mathrm{~ms}^{-1}$, conductor temperature of $75^{\circ} \mathrm{C}$ and ambient temperature of $30^{\circ} \mathrm{C}$. Further, the rated power output of the wind farm is used for this design.

$\left[\frac{P_{\text {wind_farm }}}{\sqrt{3} \times 33 \times 10^{3} \cos \phi}+I_{\text {safety_margin }}\right]^{2} R_{a c}+q_{s}=q_{c}+q_{r}$

where

$P_{\text {wind } \_ \text {farm }}$ is the power output of the wind farm

$\cos \phi$ is power factor and was taken as 0.9

$I_{\text {safety_margin }}$ is a safety margin used for the design

The proposed conductor design is based on equation (11) with the actual wind speed at the tower height (wind speed measurements from the turbine was reduced using the $1 / 7^{\text {th }}$ rule), the conductor temperature of $75^{\circ} \mathrm{C}$ and ambient temperature of $30{ }^{\circ} \mathrm{C}$. The design current is not based on the wind farm output but on the rated power output of each wind turbine. The multiplier $n$ is 1 when considering the line section $\mathrm{AB}, 7$ when considering the line section $\mathrm{GH}$, and 8 when considering the line section from $\mathrm{H}$ to grid.

$$
\left[I_{\text {design }}\right]^{2} R_{a c}+q_{s}=q_{c}+q_{r}
$$

where 


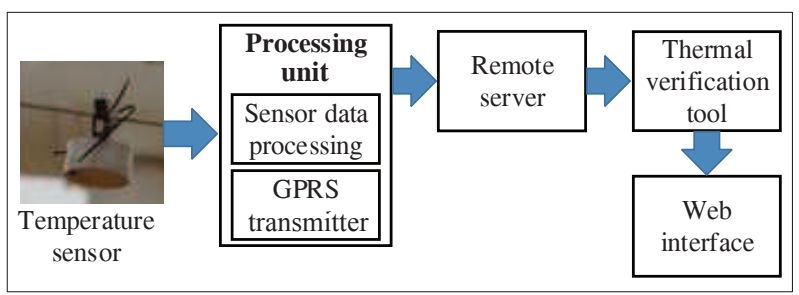

Figure 4: Temperature sensor and integrated thermal verification tool

$$
I_{\text {design }}=\frac{n P_{\text {wind_turbine }}}{\sqrt{3} \times 33 \times 10^{3} \cos \phi}+I_{\text {safety_margin }}
$$

\section{Real time system to ensure the safe operation of the collector network}

The block diagram of the system shown in Figure 4 was implemented. The conductor temperature values are first sensed and then sent to a remote server. The verification tool takes the measured $T_{c}$ as an input and the core temperature of the conductor was calculated in near real time.

\section{Sensing device}

To measure the conductor temperature, a cost effective sensing device was designed and implemented. LM 35DZ analog temperature sensor, which is a precision integrated-circuit temperature sensor that is widely available, low in cost, and small in size, was selected as a suitable temperature sensor. The sensor does not require any external calibration or trimming to provide typical accuracies of $\pm 0.25^{\circ} \mathrm{C}$ at room temperature and $\pm 0.75^{\circ} \mathrm{C}$ over a full -55 to $+150^{\circ} \mathrm{C}$ temperature range. The heat is carried into the sensor by the leads of the LM35DZ sensor, which gives a voltage proportional to the temperature. To minimise the heat loss to the environment from the leads of LM35DZ sensor, they were covered by sleeves. To obtain a more accurate reading of the surface temperature of the overhead conductor, two sensors were used in a device and the average reading was taken as the measurement.

Since $33 \mathrm{kV}$ lines produce high electric and magnetic fields, it is required to cancel the field effects to the circuits, which are to be mounted. Therefore, the circuit components were mounted inside an aluminum cage, which acts as a Faraday cage. The localised electric field near a conductor can be sufficiently concentrated to ionise the air close to the conductors. This can result in a partial discharge of electrical energy called corona discharges. The corona can damage system components over time. Therefore the shape of the mounting device was designed such that it complies with the safety and operational standards of utility equipment on overhead conductor. The weight of the enclosure was also considered during the design to make sure that it will not create a significant sag in the conductor when the device is mounted. Figure 5 shows the sensing device developed.

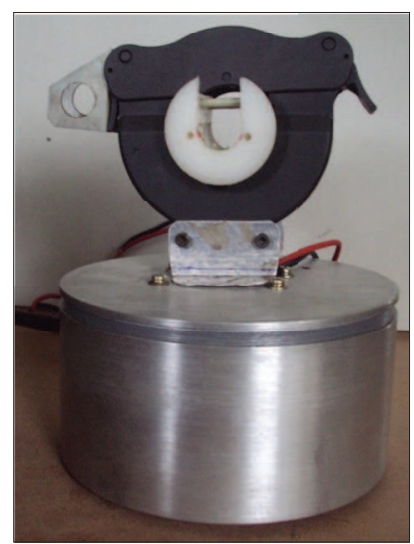

Figure 5: Sensing device with temperature and current sensing

\section{Processing unit}

The processing unit is used to process the sensor outputs and communicate the processed data to a remote server. Arduino UNO board based on the ATmega328P microcontroller was used as the processer unit. The board has 14 digital input/output pins and 6 analog inputs to connect the sensors. The analog outputs of the sensors are connected to the analog input pins and digitised by the 10-bit analog to digital converter in the Arduino UNO.

Table 1: Design current at each conductor section

\begin{tabular}{lcc}
\hline $\begin{array}{l}\text { Transmission } \\
\text { conductor section }\end{array}$ & $\begin{array}{c}\text { Number of wind } \\
\text { turbines connected }\end{array}$ & $\begin{array}{c}\text { Design current }\left(I_{\text {design }}\right) \\
(\mathrm{A})\end{array}$ \\
\hline AB & 1 & 83.38 \\
BC & 2 & 156.37 \\
CD & 3 & 222.05 \\
DE & 4 & 287.74 \\
EF & 5 & 316.93 \\
FG & 6 & 375.32 \\
GH & 7 & 433.71 \\
H - to grid & 8 & 492.09 \\
\hline
\end{tabular}




\section{Data communication}

Once the sensor readings are processed, they were sent to a ground station for further calculations. The requirement of the communication unit is wireless transmission of data to a $\mathrm{PC}$ or a phone from a maximum distance of $5 \mathrm{~km}$. To obtain measurements from the devices connected on the overhead conductor to a centralised ground station, considering the distance between the ground station and the measuring point, GSM/GPRS technology was used. SIM900 quad-band GSM/GPRS shield was selected as it can be used as a shield for Arduino UNO. The GPRS shield provides a way to use the GSM cell phone network to receive data from a remote location.

\section{Sensor network system}

All the sensors mounted on the overhead line send the measured data to the centralised database, which is hosted in a remote server. The database tables were created separately using MySQL for each device according to the number of sensors in the device. Connecting the database and the server request sent by the GPRS shield is done by PHP programme. The web interface was also developed with HTML to display the real time data in the server database received from the devices. These measurements were used to ensure that the conductor operates safely without violating the condition: 'core temperature $<$ maximum allowable temperature' in real time.

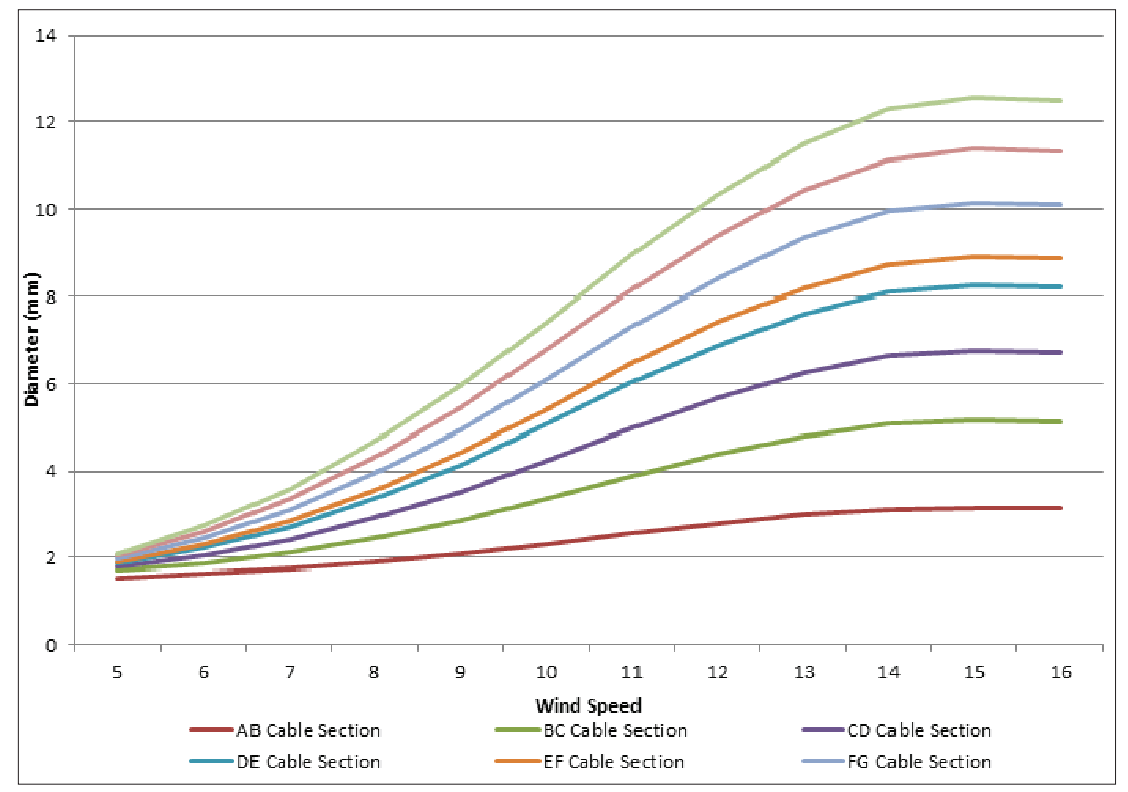

Figure 6: Conductor diameter values for each conductor section

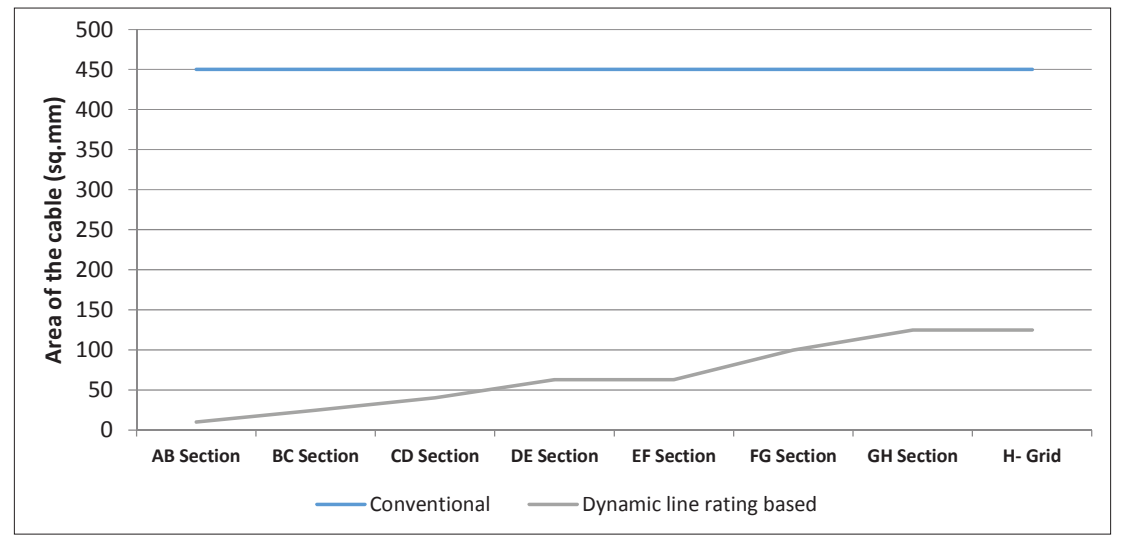

Figure 7: Comparison of cable design methods 

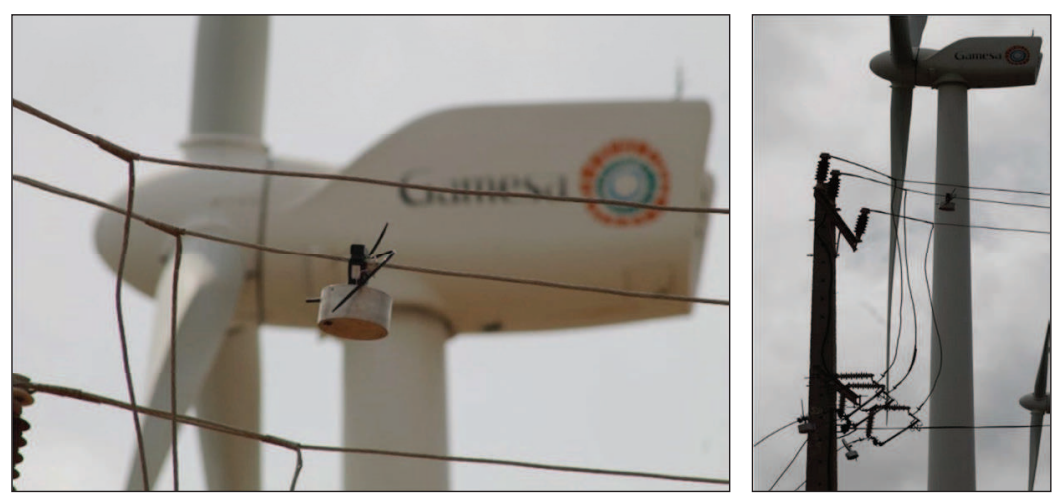

Figure 8: Devices mounted on a wind turbine collector conductor

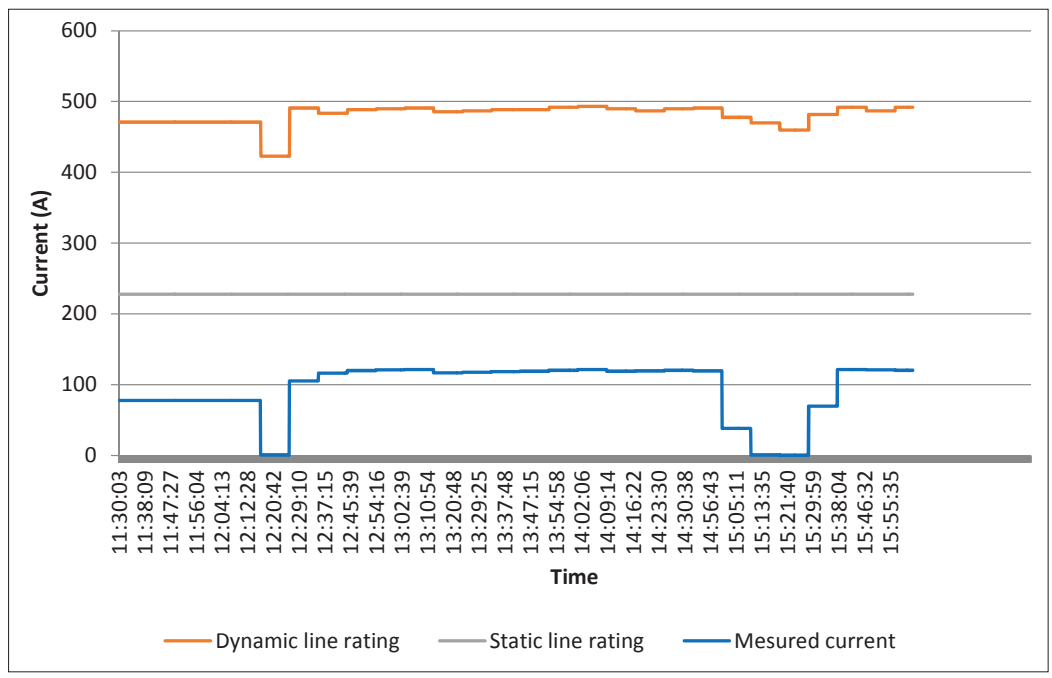

Figure 9: Dynamic and static line ratings and actual current

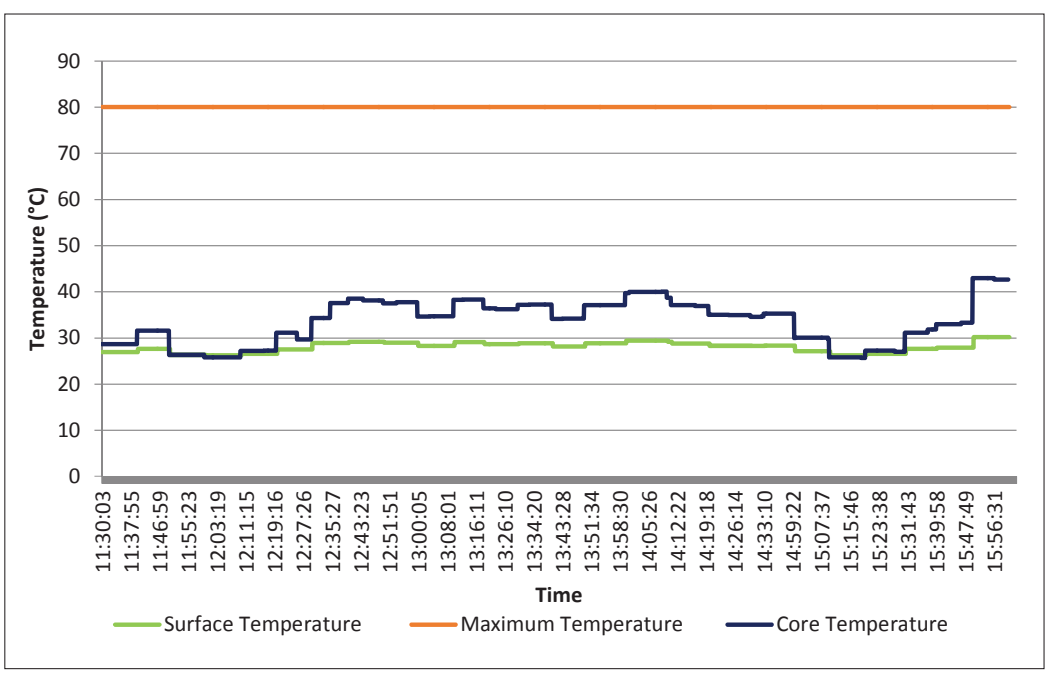

Figure 10: Conductor core temperature and maximum allowed temperature 


\section{RESULTS AND DISCUSSION}

\section{Wind farm collector conductor design}

This section presents the results of the collector conductor design for the wind farm shown in Figure 3. The design current used for the tapered design for each line section with a safety margin of $25 \mathrm{~A}$ is given in Table 1 .

Figure 6 shows the cross sectional area required for each line section for different wind speeds. Figure 7 shows the cross sectional areas selected based on conventional and proposed methods. For these designs load flow studies were conducted to make sure that the voltage at anywhere on the collector network does not violate the design limits, i.e. 0.9 pu to $1.1 \mathrm{pu}$. For load flow studies, both resistance and reactance of the line were considered.

This case study clearly demonstrated that the size of the collector cables calculated using the proposed method is much less than that is calculated based on the current practice. This in turn minimises the capital cost (CAPEX) required for cables.

Testing the real time system developed in a $33 \mathrm{kV}$ collector network of a wind farm

The field testing of the real time system described previously was carried out in a $10 \mathrm{MW}$ wind farm collector network (that was designed based on the static rating). The devices were mounted at the output of the wind turbine generator transformer. At each phase of the $33 \mathrm{kV}$ three phase conductors, devices were mounted as shown in Figure 8.

The real time surface temperature was obtained using the system shown in Figure 4. Figure 9 shows the dynamic line rating obtained from the designed tool, the static rating of the conductor, and the actual current flowing in the conductor. Figure 10 shows the conductor temperature obtained from the verification tool and the maximum allowable core temperature.

\section{CONCLUSION}

Although the cost of the collector network in a wind farm is about $5-10 \%$ of the total CAPEX of the wind farm, any reduction of $\mathrm{Cu}$ or $\mathrm{Al}$ used for conductors is welcomed both by the environmental and cost point of views. Therefore, the selection of conductors for the collector network plays an important role in wind farm design.
Two tools, a design tool and a verification tool, were developed. The design tool enables designing of the optimum collector network for the wind farm based on the dynamic line rating of the conductor and tapered current ratings. The verification tool together with the sensing devices was used to make sure that a network designed using the dynamic line rating operates safely such that the core temperature of the conductor does not violate the maximum allowable conductor temperature in real time.

The case study used for the design clearly demonstrated that the size of the collector conductors obtained using the dynamic line rating and tapered design is much less than that is calculated based on the current practice.

Although the verification tool was not used to demonstrate its real purpose, the real life implementation in a $10 \mathrm{MW}$ wind farm demonstrated that the system can work in near real time and compare the near real time core temperature with the maximum allowable values. The measurements obtained also clearly showed that the margin between the dynamic line rating and the actual current, and the margin between the actual temperature and the maximum allowable temperature are considerably high. This clearly suggests that the design based on the static rating leads to underutilisation of conductors.

\section{Acknowledgement}

The authors would like to acknowledge the financial support provided by the National Science Foundation, Sri Lanka under the research grant RG/2014/EA \& ICT/01. The Sri Lanka Technology Campus is acknowledged for the continuing support provided to expand this research. Authors would also like to thank Wind Force Pvt. (Ltd.) for giving access to the wind farm and providing fullest support to collect data.

\section{REFERENCES}

1. Afanasyeva S., Karppanen J., Saari J., Partanen J. \& Pyrhönen O. (2016). Integrated approach to the design of wind farm infrastructure. IEEE PES Innovative Smart Grid Technologies Conference Europe, Ljubljana, Slovenia, 9 12 October, pp. $1-6$.

DOI: https://doi.org/10.1109/ISGTEurope.2016.7856294

2. Bradt M. et al. (25 authors) (2010). Design and application of cables and overhead lines in wind power plants. IEEE PES Transmission and Distribution Conference and Exposition, New Orleans, USA, 19 - 22 April, pp. 1 - 6. DOI: https://doi.org/10.1109/TDC.2010.5484317 
3. Camm E.H. et al. (23 authors) (2009a). Wind power plant collector system design considerations. Power and Energy Society General Meeting, Calgary, Canada, 26 - 30 July, pp. $1-7$.

4. Camm E.H. et al. (23 authors) (2009b). Wind power plant substation and collector system redundancy, reliability, and economics. Power and Energy Society General Meeting, Calgary, Canada, 26 - 30 July, pp. $1-6$.

DOI: https://doi.org/10.1109/PES.2009.5275333

5. Cerveira A., de Sousa A., Pires E.J.S. \& Baptista J. (2016). Optimal cable design of wind farms: the infrastructure and losses cost minimization case. IEEE Transaction on Power Systems 31(6): 1 - 11.

DOI: https://doi.org/10.1109/TPWRS.2016.2521700

6. Deb A.K. (2000). Power line ampacity system: theory, modeling, and applications. CRC Press, Boca Raton, Florida, USA.

7. Douglas D.A., Edris A. \& Pritchard G.A. (1997). Field application of a dynamic thermal circuit rating method. IEEE Transactions on Power Delivery 12(2): 823 - 831. DOI: https://doi.org/10.1109/61.584390

8. Dutta S. \& Overbye T.J. (2011). A clustering based wind farm collector system cable layout design. IEEE Power and Energy Conference at Illinois, USA, 25 - 26 February, pp. $1-6$. DOI: https://doi.org/10.1109/PECI.2011.5740480

9. Dutta S. \& Overbye T.J. (2012). Optimal wind farm collector system topology design considering total trenching length. IEEE Transactions on Sustainable Energy 3: 339 - 348. DOI: https://doi.org/10.1109/TSTE.2012.2185817

10. Dutta S. \& Overbye T.J. (2013). A graph-theoretic approach for addressing trenching constraints in wind farm collector system design. IEEE Power and Energy Conference at Illinois, USA, 22 - 23 February, pp. 48 - 52.

DOI: https://doi.org/10.1109/PECI.2013.6506033

11. Enrique E.H., Wier T. \& Haub P.N. (2014). Thermal capacity of collector system feeders in wind farms. IEEE
Conference on Technologies for Sustainability, Portland, USA, 24 - 26 July, pp. 155 - 159.

DOI: https://doi.org/10.1109/SusTech.2014.7046236

12. IEEE Standard $738^{\mathrm{TM}}$ (2012). IEEE standard for calculating the current-temperature relationship of bare overhead conductors. IEEE Power and Energy Society, 23 December, pp. $1-72$.

13. Jenkins N. \& Ekanayake J. (2017). Renewable Energy Engineering. Cambridge University Press, Cambridge, UK.

14. Johnson K.L. (1985). Contact Mechanics. Cambridge University Press, Cambridge, UK.

DOI: https://doi.org/10.1017/CBO9781139171731

15. Kiessling F., Nefzger P., Nolasco J.F. \& Kaintzyk U. (2003). Overhead Power Lines: Planning, Design, Construction. Springer-Verlag, Berlin, Germany.

DOI: https://doi.org/10.1007/978-3-642-97879-1

16. Morgan V.T. (1990). The radial temperature distribution and effective radial thermal conductivity in bare solid and stranded conductors. IEEE Transaction on Power Delivery 5(3): 1443 - 1452.

DOI: https://doi.org/10.1109/61.57987

17. Power Delivery Consultants Inc. (2013). Overhead Lines FAQ. Available at http://pdc-cables.com/oh_dynamic_faq. html, Accessed 25 May 2017.

18. Rosen B., Davis M. \& Maples T. (2010). Cost-Saving Approaches to Wind Farm Design: Exploring CollectionSystem Alternatives Can Yield Savings, available at http:// www.burnsmcd.com/BenchMark/Article/Cost-SavingApproaches-to-Wind-Farm-Design. Accessed 25 May 2017.

19. Wu Y.K., Lee C.Y., Chen C.R. \& Tsai S.H. (2011). Onshore wind farm planning and system simulation analysis under low carbon - island project at penghu. $16^{\text {th }}$ International Conference on Intelligent System Application to Power Systems, Hersonissos, Greece, 25 - 28 September, pp. 1 - 7. DOI: https://doi.org/10.1109/ISAP.2011.6082178 